Original Article

\title{
Cationic topical formulations tested in high dilutions offers protective effects in fibroblast cells culture
}

\author{
Danielle de Macedo Mano ${ }^{1,2}$, Érika Cristina Vargas de Oliveira ${ }^{1,2}$, \\ Alexandre Henrique Leonel2,3,4, Andresa Aparecida Berretta ${ }^{2}$ \\ (1) University of São Paulo, Ribeirão Preto, Brazil \\ (2) Instituto Homeopático François Lamasson, Ribeirão Preto, Brazil \\ (3) University of Franca, Franca, Brazil \\ (4) CEO on Homeopatia Brasil, Franca, Brazil
}

\begin{abstract}
Topical administration is a simple and comfortable form of cutaneous administration of drugs. However, in this route of administration the drug needs to overcome the barrier posed by the skin to reach an effective concentration. For this reason, many topical formulations are developed with a cationic component. The promotion of absorption occurs due to the disruption of the stratum corneum. But this cationic component has also high irritating potential to the skin. The biotherapics are medicines prepared from a toxic product or etiologic agent, following the homeopathic pharmacopoeia technique, and they are used mainly in cases of hipersensitization. In this experiment, high dilutions (HD) obtained from a cationic formulation were prepared and evaluated considering cell viability in "in vitro" mouse fibroblast (L929) culture cells model by a colorimetric MTT assay. No signs of toxicity were observed, which demonstrates the safety of these HD preparations to the healthy cells. The effectiveness of these HD was also investigated in cells damaged by cationic formulations. The results demonstrated that the HD 30c was the most effective preparation in preventing the cell damage caused by the tested irritating product, increasing cell viability from $56.6 \%$ (damaged cells) to $100 \%$ (similar to negative control group, $\mathrm{p}>0.05$ ). These results provide evidence of the positive action of high dilutions against the exposure to a cytotoxic agent.
\end{abstract}

Keywords: Biotherapics. Cell Culture. High dilutions.

\section{Introduction}

The administration of compounds in the skin is extremely attractive, because it has a local effect (topical administration) which is effective and safe - as well as a systemic effect (transdermal administration), combining the patient's convenience with the absence of hepatic first-pass effects and systemic adverse effects. However, the penetration of macromolecules through the skin is difficult because of the tissue's barrier properties exerted mainly by the stratum corneum [1].

The surface of any tissue, including the stratum corneum, has a cellular membrane constituted of anionic domains, resulted from the presence of negative charged phospholipids and proteoglycans, which gives the skin characteristics of a negatively charged membrane [2,3]. One way of enhancing penetration of molecules through the skin is by the use of compounds which give a residual positive charge to the formulation. By electrostatic interactions, the formulation positive compounds interacts with the negative charge of the 
membrane, favoring the adsorption of the particle into the skin surface[4,5]. On the other hand, this efficacy in promoting the cutaneous absorption is also followed by in vitro and in vivo toxicity[6].

Several researchers who have studied the structural properties of this positive charge associate this toxicity with some effects caused by primary amines, such as: enhance of permeability as a result of the change of the membrane's fluidity, caused by the interaction between the cationic particle and cell surface, which breaks the bilayer integrity due to disruption of tight junction[2,3]; change of critical intracellular processes; disruption protein kinase $\mathrm{C}$ function; and the effect of amines on intracellular organelles[7].

Despite the lack of information regarding the exact mechanism that leads to toxicity, there are many reports which correlate dose of cationic compound / cellular toxicity, suggesting that the high positive charge density is one of the factors of toxicity [7-11].

Therefore, in one hand, the use of cationic formulations may increase the permeation of a drug, favoring the treatment and, on the other hand, the toxicity derived from these formulations may limit their use, causing cutaneous irritation and discomfort to the patient.

A major area of research in homeopathy is related to the use of high dilutions (HD) of substances, notably allergens or irritant compounds, in order to prevent or to cure the same allergy or irritation[12]. When these compounds are diluted and agitated, they are called biotherapics. The biotherapics have a much more specific application than other homeopathic medicines, usually for a particular disease, rather than having a broad indication for the mental, emotional and physiological aspects. Its use in the treatment or prophylaxis of diseases has been investigated by many researchers who have reported a beneficial effect on disease progression [13-19].

Hence, experimental results obtained with HD of Trypanosoma cruzi [18,20] indicate that its administration in mice, as a preliminary step to infection by parasites, was able to stimulate the immune system of the treated animals [21,22] leading to the infection control.

The biotherapics are more easily tested because unlike classical homeopathy, the same remedy is administrated to all patients (in contrast with the system of individualized homeopathy). This makes the analysis of the results simpler and reproducible [23], and enables the in vitro study [24,25].

The similia principle, in its most basic form, can be tested at the cellular level by the determination of the extent of cell recovery when stimulated by a small dose of the substance which, at first - at high concentrations- is responsible for deregulating the system. What must be assessed is whether the stimulus is able to increase survival cells [26].

The aim of this study was to develop a HD through a topical cationic formulation and to evaluate the efficacy of this HD in reducing the in vitro toxicity of this cationic formulation. For such study, it was employed culture of mouse fibroblast cells (L929), which is classically described as a model for safety assessment of topical drugs [27].

\section{Materials and methods}

All experiments were performed at the University of São Paulo, Faculty of Pharmaceutical Sciences of Ribeirão Preto, after being previously authorized by the professors responsible for each laboratory where the research took place. 


\section{Preparation of the high dilutions}

The high dilutions were prepared following the instructions of the Brazilian Homeopathic Pharmacopoeia ( $3^{\text {rd }}$ Edition) for soluble substances. Two scales were used. A first dilution was prepared using $1 \mathrm{~mL}$ of cationic formulation, previously obtained with polyethylenimine (PEI) by Mano [28] and using 9mL of sterile distilled water, in order to make the first dilution (1:10 dilution - scale $\mathrm{x}$ ). This 1:10 sample was submitted to 100 manual agitations, so as to produce the first decimal dilution (1x). One $\mathrm{mL}$ of this solution was diluted in $9 \mathrm{~mL}$ of water, after 100 manual agitations another dilutions was prepared. This procedure was successively repeated until it was obtained an 11x. Another dilution adopted was prepared using $0,1 \mathrm{~mL}$ of cationic formulation and using 9,9mL of sterile distilled water (1:100 dilution - scale c). The sample was also submitted to 100 manual agitations, until 29c dilutions. The HD of the last dilution in each scale was prepared in culture medium Dulbecco's Modified Eagle Medium (DMEM, Gibco).

\section{Cell line and cell culture}

Mouse fibroblasts cell line (L929) were selected for this study. Cells were cultured in DMEM supplemented with $100 \mu \mathrm{g} / \mathrm{mL}$ streptomycin, $100 \mathrm{units} / \mathrm{mL}$ penicillin and $10 \%$ fetal bovine serum (FBS - Gibco, Invitrogen, USA), in a humidified, $5 \%(\mathrm{v} / \mathrm{v}) \mathrm{CO}_{2}$ atmosphere. The cultures were grown in monolayer at $37^{\circ} \mathrm{C}$ until reach confluence.

\section{Incubation of L929 cells with HD}

Confluent L929 cells were seeded into a 96 -well plate $\left(0.5 \times 10^{5}\right.$ cells/well) and kept in incubation for 24 hours. The HD 30c or 12x was applied every 4 hours, comprising, at the end of the study, $15 \%$ of the final volume of the culture well. The experimental protocol was:

- Group 1/ negative control: cells without any treatment

- Group 2/ positive control: cells with irritant cationic preparation

- Group 3/ cells incubated with HD 12x

- Group 4/ cells incubated with HD 30c

At the groups 2, 3 and 4 it was applied $20 \mu \mathrm{L}$ of topic cationic formulation (diluted 1:50 in phosphate buffer solution, PBS pH 7,2) after confluence cells. Note that the cells that were not treated with the HD received $5 \mu \mathrm{L}$ of culture medium every 4 hours.

\section{Cells Viability}

The viability of the cell line as a response to previous incubation of cells with HD was evaluated by the MTT assay, using 3-(4,5-dimethylthiazol-2-yl)-2,5-diphenyl tetrazolium bromide (MTT, Sigma-Aldrich).

The MTT method measures the mitochondrial activity of viable cells. This method is sensitive to measure the viability and cellular activity. The principle of this method consists in the absorption of salt MTT by the cells, which is reduced inside the mitochondria to a product called formazan. This product has purple coloration and it is accumulate inside the cell. After the solubilization of formazan in solvent dimethylsulfoxide (DMSO), it can be quantified in a spectrophotometer ELISA reader $(\chi=570 \mathrm{~nm})$. Changes in cell mitochondrial activity result in changes in the amount of formazan produced. This change in the amount of formazan produced results in a change of absorbance, which allows quantifying mitochondrial activity of L929 cells in the different experimental condition [29]. 
Under the experimental conditions tested, after a period of contact with the cationic topical formulation, it was added $20 \mu \mathrm{L}$ of MTT $\left(5.0 \mathrm{mg} / \mathrm{mL}\right.$ in PBS) for 4 hours at $37^{\circ} \mathrm{C}$ in the absence of light. Then, the supernatant was removed and formazan crystals were dissolved with $200 \mu \mathrm{L}$ of DMSO. The absorbance was measured in each well in 570nm ( $\mu$ Quant, Biotek Instruments Inc.) [30,31]. The cell viability of each group was expressed as a percentage relative to the negative control group (Group 1) considered as $100 \%$ cell viability.

\section{Morphological Changes of Cell Culture}

Morphological features of treated and untreated cells were assessed through microscopy. For the analysis of cellular changes, a higher density of cells $\left(1 \times 10^{6}\right.$ cells/well $)$ was seeded on coverslips in 6 -well plate. However, it was used the same experimental protocol adopted in the determination of cell viability.

The coverslips were examined with a light microscope (model Axio Imager A1, Carl Zeiss AG, Germany) coupled to a camera with image analysis software (AxioVision Model, Carls Zeiss) using the objective of 20 times.

\section{Statistical Analysis}

Data is presented as the mean \pm SEM. Multiple comparisons were performed using one-way of variance (ANOVA) followed by Newman-Keuls test in order to determine the level of significance of the differences. The results have $95 \%$ as a minimum confidence, a significant difference being greater than $0.05(p<0,05)$.

\section{Results}

\section{Cell viability with HD}

The results obtained with the MTT assay were determined by a control (Group 1: cells that did not receive any treatment). This method showed that incubation with HD does not change cell viability (Figure 1), since there was no statistically significant difference ( $>0.05$ ) between groups incubated with HD and the control cells.

\section{Cell Viability}

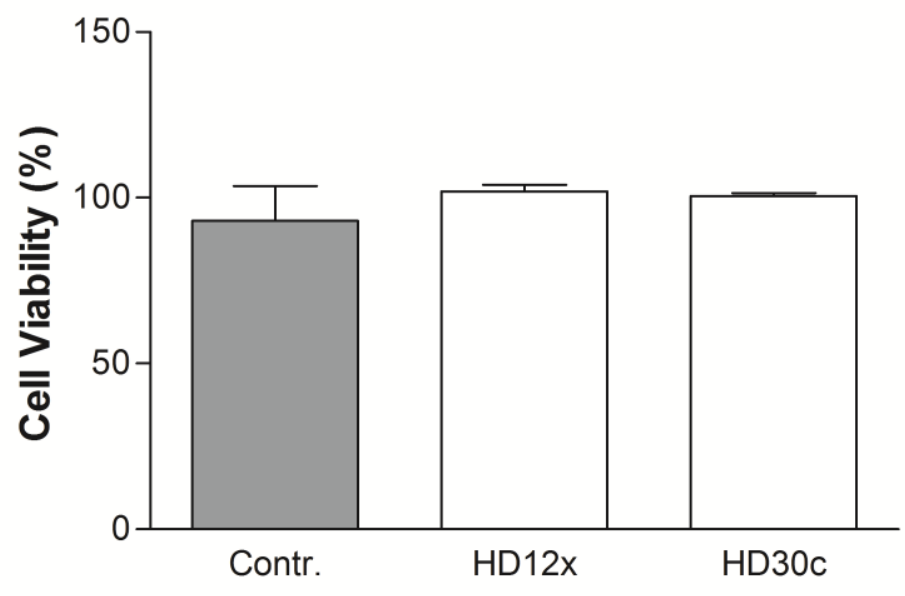

Figure 1: Effect of incubation with high dilutions at cell viability of the strain fibroblasts L929. The results represent the average of six determinations \pm SEM. Statistical analysis performed by nonparametric Newman-Keuls. 
After the incubation with HD, the cells were treated with a cationic formulation. Then, after 24 hours, the MTT assay was performed. The cell viability was analyzed as a response to the contact with the cationic formulation (Figure 2). These results showed that the incubation with HD (in the two potencies analyzed) before the contact with cationic formulation promoted a protection in cell. The group that did not receive the HD (Group 2) had the reduction on cell viability. However, the groups which were incubated with HD showed resistance to the stress: Group 3 (HD 12x) had an increase in cell viability, and Group 4 (HD 30c) did not alter the cell viability.

\section{Cell Viability}

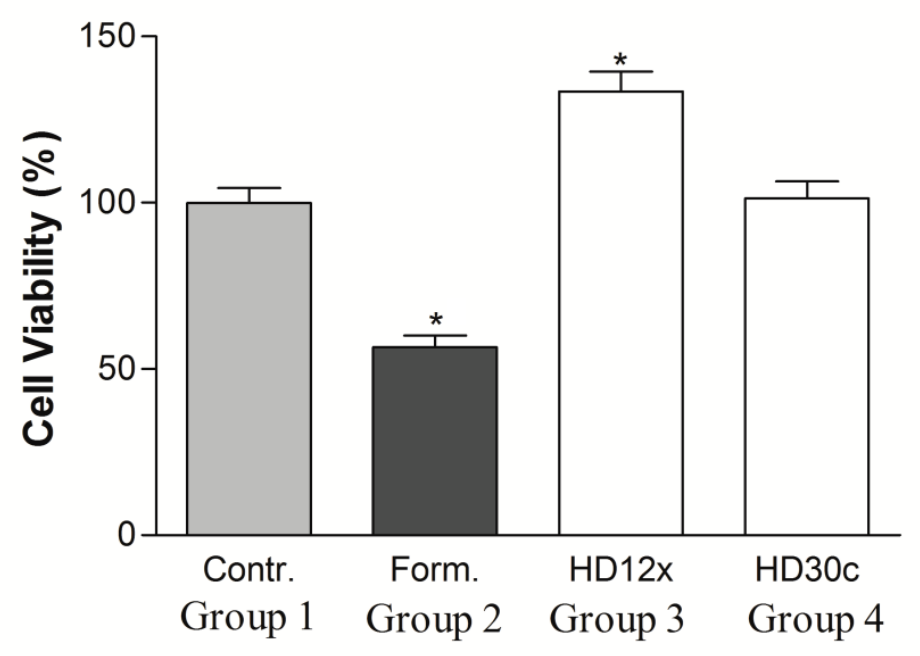

Figure 2: Effect of incubation with high dilutions at cell viability of the strain fibroblasts L929 after contact with cationic formulation. The results represent the average of six determinations \pm SEM. Statistical analysis performed by nonparametric Newman-Keuls, ${ }^{*}$ p $<0.001$ compared to control (untreated cells).

\section{Morphological Changes of Cell Culture}

In order to analyze the morphology of cell culture, the cells were observed under the microscope. Observation of these cell showed that cell morphology changes after the cells were exposed to the formulation (Figure 3). Only the incubation with the HD was not able to change the morphology (as it was showed in $\mathbf{A}, \mathbf{B}$ or $\mathbf{C}$ in Figure 3). It can be observed cytoplasmic spindle in these cells (as shown by arrows), since L929 fibroblast is an adherent type of cell. The cell viability was reduced after the use of cationic formulation, which was observed in cell morphology too. Figure 3 A' shows less amounts of cells and also many of these cells are spherical (indicated by circles), which indicates stress. Additionally, it can be observed a reduced cytoplasmic spindle, since the cell death consequently reduces adherence. Once the cell dies, it loses the adherence with the culture vessel and stays in suspension. In Figure 3 B' the number of cells is larger than the control, and the morphology of these cells shows the cells in a proliferation phase, with bigger nucleus. Lastly, in Figure 3 C' the number of cells is visually the same of the control (Figure $3 \mathrm{~A}$ ), but with morphological changes, the cells are thinner and there are smaller cytoplasmic spindle cells.

It is important to consider that the cell viability in Group 4 is almost equal to the control (Group 1), even after the addition of a cationic formulation. So, it shows that in this case the cells have the tendency to support the stress and not to have so strong response in comparison with Group 3. Group 2 demonstrates the cell death as a consequence of irritating cationic formulation and group 3 shows a burst of proliferation. Based on these findings it could be suggested that $30 \mathrm{c}$ is the best HD studied. 

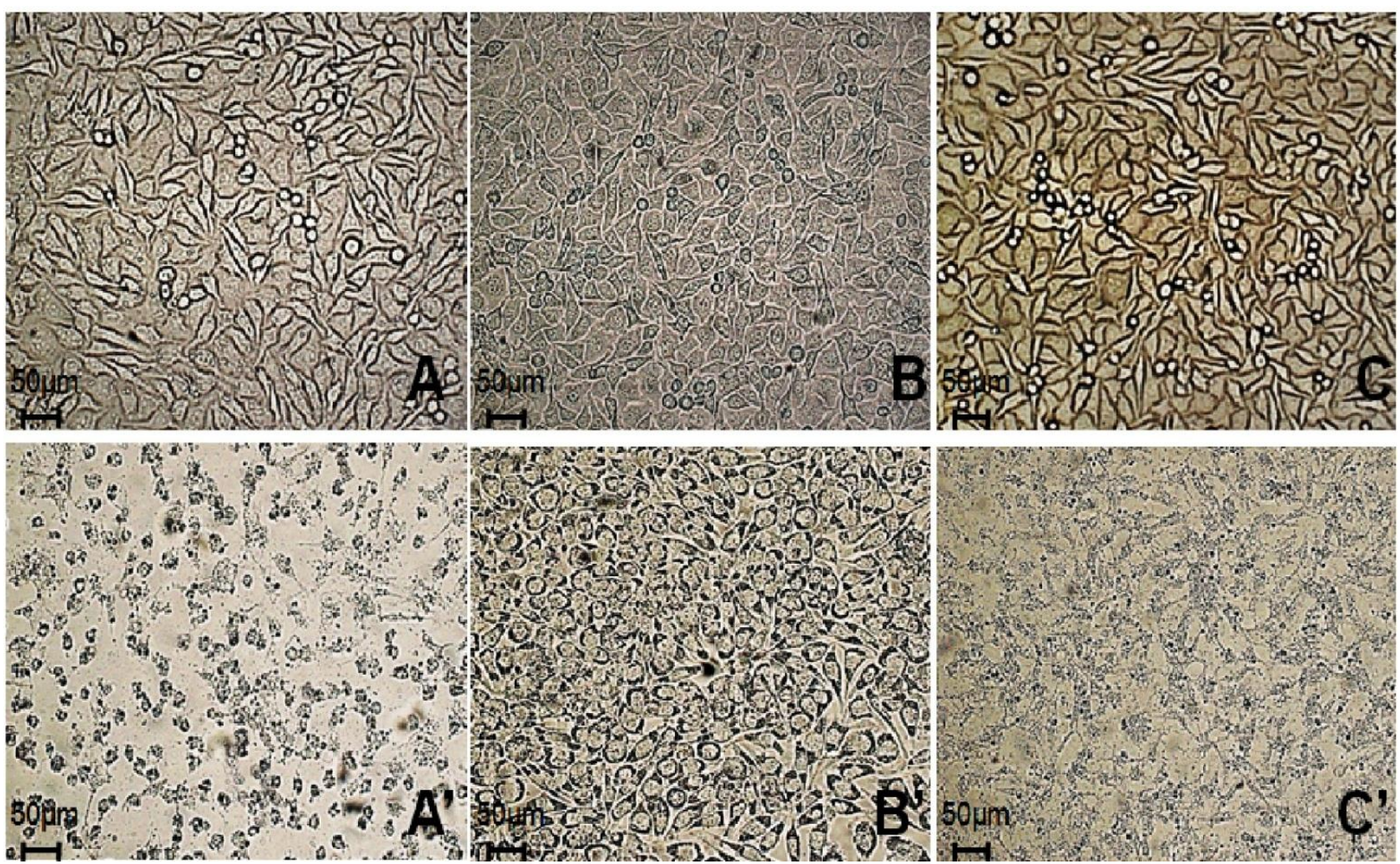

Figure 3: Microscope characteristic of cell line L929 incubated with high dilutions, after treatment with cationic formulation. Increased 20x. Cell culture of fibroblasts control (no incubation with HD) (A) cells at incubation with HD12x (B) and with HD30c (C). (') indicates the respective cells after receiving the cationic formulation for $24 \mathrm{~h}$.

\section{Discussion}

\section{Cell viability with HD}

When the HD was incubated with cells, the cell survival did not change in comparison with the control (Figure 1). Therefore, when the HD was added to cell culture the response of this cell culture did not change demonstrating that HD preparations are safety for topical application. This result is important because it proves that any cell response comes after a cell aggression, after the contact with cationic formulation and that the damage observed were not related to HD preparations.

\section{Effect of HD on cells damaged with cationic formulation}

The propensity of mammalian cells to internalize positive charge with the intracellular traffic, allowing a direct entry into the cell, can weaken the membrane's structure and the function of organelles [31], and may induce apoptosis because of the destabilization mitochondrial membrane [34]. Cells with stress or damage suffer changes in homeostatic balance, which results in enhanced sensitivity [32,33]. Due to this enhanced sensitivity, cells react to stimuli to which they normally would not react [33]. The cell viability was analyzed as a response to the contact with the cationic formulation (Figure 2), since this formulation is related to a cellular toxicity effect [7-11, 35].

The positive control cells that received culture medium every four hours (Figure 2 - Group 2) and received cationic formulation in the end, have a cellular viability of $56.6 \% \pm 7.7$. Contrarily, the cells which were previously incubated with HD of this formulation, after being in contact with the cationic formulation, had higher cell viability results. This analysis showed that the L929 cells, after receiving the stimulation of the HD formulation, had their cellular respiration rate significantly increased. So, it indicates an activation of 
mitochondrial enzymes when cells are under the stimulus of HD. When HD is diluted in 30c, cell viability was $(100 \pm 17) \%$, showing no significant difference compared to control (cells not receiving the formulation). Therefore, incubation with the dilution form of the formulation protected the cells against aggression caused by the contact with the formulation. After using dilution of $12 \mathrm{x}$, cell viability was $(138 \pm 15) \%$, showing a cell proliferation compared to untreated control. This proliferation is a result of the increase in oxidative metabolism, often a temporary effect, after which the cell returns to its normal metabolism $[24,36]$. The similia principle occurs at the cellular level by a correlation between the stress caused (the symptom in molecular terms) and the degree of stimulation of the self-recovery [37,38].

The homeopathic stimulus is able to induce a secondary response in the body, causing a change in its metabolic parameters, which are able to intervene in how biological defense and recovery will be adjusted, by stimulating the recovery process and increasing resistance $[26,39,40]$. Thus, the results of the MTT experiments in L929 cells incubated with HD suggest the ability to activate the Krebs cycle, causing an increase in energy production as well as in the generation of amino acids for protein synthesis, common situations to cells that have increased rates of proliferation, protecting cells from death [41,42].

\section{Morphological Changes of Cell Culture}

In Figure 3 it is possible to see the morphological characteristic of fibroblasts. Fibroblasts are spindle cells with central nucleus and typical cytoplasmic processes. It could be observe that there was no morphological changes after cells were incubated with HD (Figures 3 B and C).

After being in contact with the cationic formulation it could be observed that the cell morphology has changed. In Figure $3 \mathrm{~A}^{\prime}$ one can see spherical cells (circles in the figure). The refringence displayed in the image indicates cellular metabolism, but the cell could be heading towards cell death, which can be inferred by the loss of cytoplasmic extension and the cell in suspension. Figure 3 B' (cell incubated with HD 12x) shows the cell growth stimulated after being in contact with the aggressor factor (cationic formulation), as seen in MTT, which can be perceived by morphological appearance of the cells. In this image the fusiform format cells is kept and the nucleus has a larger volume, suggesting cell division. Incubation of cells with HD 30c (Figure 3 C') also caused the change of their morphology. However, morphological change is less pronounced. It is still possible to see the cytoplasmic spindle (arrows in Figure 3C') and the fusiform format but with a low cytoplasmic volume.

In order to assess whether the stress suffered by the cell is reversible, after cell treatment with the formulation, cells were washed with saline and they were left in culture medium under optimal conditions for growth. Cell growth was then monitored. Through this analysis we found that cellular stress, which leads to morphological changes, was temporary. After removing the cellular toxicity factor, the cells began to grow again, though at a slower pace. The cells returned to their characteristic morphology 2 days faster in cells that were incubated with HD, in comparison with cell control, which receive just medium culture (cells with HD spent 3 days to begin to grow again, while positive control cells started to grow again in 5 days). This analysis shows that the cells are viable after being in contact with the cationic formulation.

\section{Conclusion}

The conventional chemical characterization of formulation, which means the dosing of the drug, cannot be accomplished in a HD. Despite this limitation, the assay involving culturing fibroblast cells showed the activity of HD when examined in cell viability after being exposed to a cytotoxic agent. It was demonstrated, in this model, that both HD preparations evaluated were safe to cell culture and additionally, cationic formulations tested in high dilutions offered protective effects in fibroblast cells culture damaged with irritating formulation, especially 30c. Therefore, the effects of HD can be demonstrated by scientific methods. 
These promising results show the biological effects of high dilutions, which suggest the possibility of future studies in clinical trials.

\section{References}

[1] Prausnitz MR, Mitragotri S, Langer R. Current status and future potential of transdermal drug delivery. Nature reviews. Drug discovery. 2004;3(2):115-24.

[2] Gillet A, Compère P, Lecomte F, Hubert P, Ducat E, Evrard B, et al. Liposome surface charge influence on skin penetration behaviour. International Journal of Pharmaceutics. 2011;411(1-2):223-31.

[3] Nam J, Won N, Bang J, Jin H, Park J, Jung S, et al. Surface engineering of inorganic nanoparticles for imaging and therapy. Advanced Drug Delivery Reviews. 2012;1-27.

[4] Baspinar Y, Borchert HH. Penetration and release studies of positively and negatively charged nanoemulsions--is there a benefit of the positive charge? International Journal of Pharmaceutics. 2012;430(12):247-52.

[5] Peira E, Carlotti ME, Trotta C, Cavalli R, Trotta M. Positively charged microemulsions for topical application. International Journal of Pharmaceutics. 2008;346(1-2):119-23.

[6] Brownlie A, Uchegbu IF, Schätzlein A G. PEI-based vesicle-polymer hybrid gene delivery system with improved biocompatibility. International Journal of Pharmaceutics. 2004;274(1-2):41-52.

[7] Gao JQ, Zhao QQ, Lv TF, Shuai WP, Zhou J, Tang GP, et al. Gene-carried chitosan-linked-PEI induced high gene transfection efficiency with low toxicity and significant tumor-suppressive activity. International Journal of Pharmaceutics. 2010;387(1-2):286-94.

[8] Huang FW, Wang HY, Li C, Wang HF, Sun YX, Feng J, et al. PEGylated PEI-based biodegradable polymers as non-viral gene vectors. Acta biomaterialia. 2010;6(11):4285-95.

[9] Liang CH, Chou TH. Effect of chain length on physicochemical properties and cytotoxicity of cationic vesicles composed of phosphatidylcholines and dialkyldimethylammonium bromides. Chemistry and physics of lipids. 2009;158(2):81-90.

[10] Shen Y, Wang B, Lu Y, Ouahab A, Li Q, Tu J. A novel tumor-targeted delivery system with hydrophobized hyaluronic acid-spermine conjugates (HHSCs) for efficient receptor-mediated siRNA delivery. International Journal of Pharmaceutics. 2011;414(1-2):233-43.

[11] Tran MA, Gowda R, Sharma A, Park EJ, Adair J, Kester M, et al. Targeting V600EB-Raf and Akt3 using nanoliposomal-small interfering RNA inhibits cutaneous melanocytic lesion development. Cancer Research. 2008;68(18):7638-49.

[12] Bellavite P, Ortolani R, Pontarollo F, Piasere V, Benato G, Conforti A. Immunology and homeopathy. 4. Clinical studies-part 2. Evidence-based Complementary and Alternative Medicine. 2006;3(4):397-409.

[13] Aabel S, Laerum E, Dølvik S, Djupesland P. Is homeopathic "immunotherapy" effective? A double-blind, placebo-controlled trial with the isopathic remedy Betula 30c for patients with birch pollen allergy. The British Homoeopathic Journal. 2000;161-8.

[14] Almeida ACDE, Fonseca YM, Soares TMP, Silva DB da, Buelta TTM, Silva GLM. Tratamento de mastite subclínica em bovinos utizando bioterapia. Revista da Universidade de Alfenas. 1999;5:199-203. 
[15] Banerjee P, Bhattacharyya SS, Pathak S, Boujedaini N, Belon P, Khuda-Bukhsh AR. Evidences of protective potentials of microdoses of ultra-high diluted arsenic trioxide in mice receiving repeated injections of arsenic trioxide. Evidence-based Complementary and Alternative Medicine. 2011;2011:391752.

[16] Berchieri A, Turco WCP, Paiva JB, Oliveira GH, Sterzo E V. Evaluation of isopathic treatment of Salmonella enteritidis in poultry. Homeopathy. 2006;95(2):94-7.

[17] Danninger T, Gallenberger K, Kraeling J. Immunologic changes in healthy probands and HIV infected patients after oral administration of Staphylococcus aureus 12c: a pilot study. The British homoeopathic Journal. 2000;89(3):106-15.

[18] Queiroz AO, Xavier SCC, Faria KG, Bernardo RR, Leit TCA. Avaliação do Bioterápico Trypanosoma cruzi 30DH : Um Estudo In Vivo. Cultura Homeopática. 2007;96(3):175-82.

[19] Braga CF, Janaína G, Falkowski S, Martins N, Aleixo DL, Araújo SM de. Biotherapic 200 DH reduces cerebral parasitism in mice infected with Toxoplasma gondii. International Journal of High Dilution Research. 2011;10(36):158-62.

[20] Almeida LR, Campos MCDO, Herrera HM, Bonamin LV, Fonseca AH. Effects of homeopathy in mice experimentally infected with Trypanosoma cruzi. Homeopathy. 2008;97(2):65-9.

[21] Basombrío MA, Besuschio S. Trypanosoma cruzi culture used as vaccine to prevent chronic Chagas' disease in mice. Infection and Immunity. 1982;36(1):351-6.

[22] Sepulveda P, Hontebeyrie M, Liegeard P, Mascilli A, Norris KA. DNA-Based immunization with Trypanosoma cruzi complement regulatory protein elicits complement lytic antibodies and confers protection against Trypanosoma cruzi infection. Infection and Immunity 2000;68(9):4986-91.

[23] Aabel S. Prophylactic and acute treatment with the homeopathic medicine, Betula 30c for birch pollen allergy: a double-blind, randomized, placebo-controlled study of consistency of VAS responses. The British Homoeopathic Journal. 2001;90(2):73-8.

[24] Bellavite P, Conforti A, Pontarollo F, Ortolani R. Immunology and homeopathy. 2. Cells of the immune system and inflammation. Evidence-based Complementary and Alternative Medicine. 2006;3(1):13-24.

[25] Wijk $\mathrm{R}$ van. The in vitro evidence for an effect of high homeopathic potencies--a systematic review of the literature. Complementary Therapies in Medicine. 2007;15(2):139-41.

[26] Wijk R van, Wiegant FAC. The similia principle as a therapeutic strategy: A research program on stimulation of self-defense in disordered mammalian cells. Alternative Therapies. 1997;3(2):33-8.

[26] Bellavite P, Ortolani R, Pontarollo F, Piasere V, Benato G, Conforti A. Immunology and homeopathy. 4. Clinical studies-part 2. Evidence-based Complementary and Alternative Medicine. 2006;3(4):397-409.

[28] Mano DM. Desenvolvimento e caracterização de sistemas de liberação tópica base de cristais líquidos com vitamina E TPGS para veiculação de siRNA na terapia gênica [dissertation]. Ribeirão Preto (Brazil): Faculty of Pharmaceutical Sciences of Ribeirão Preto, University of São Paulo; 2012. 101p.

[29] Mosmann T. Rapid colorimetric assay for cellular growth and survival: application to proliferation and cytotoxicity assays. Journal of Immunological Methods. 1983;65(1-2):55-63. 
[30] Abe K, Matsuki N. Measurement of cellular 3-(4,5-dimethylthiazol-2-yl)-2,5-diphenyltetrazolium bromide (MTT) reduction activity and lactate dehydrogenase release using MTT. Neuroscience Research. 2000;38:3259 .

[31] Scherliess R. The MTT assay as tool to evaluate and compare excipient toxicity in vitro on respiratory epithelial cells. International Journal of Pharmaceutics. 2011;411(1-2):98-105.

[32] Aquino CL, Barbosa GM, Barbosa GM, Cristina M, Antunes B, Veiga VF, et al. High dilutions of Euphorbia tirucalli L. ( AVELOZ ) modify the viability and glycolitic metabolism of cell lines. International Journal of High Dilution Research. 2008;7(24):132-9.

[33] Wiegant F, Wijk R van. The similia principle: results obtained in a cellular model system. Homeopathy. 2010;99(1):3-14.

[34] Kuo YC, Wang CC. Cationic solid lipid nanoparticles with primary and quaternary amines for release of saquinavir and biocompatibility with endothelia. Colloids and Surfaces. 2013;101:101-5.

[35] Bonner DK, Zhao X, Buss H, Langer R, Hammond PT. Crosslinked linear polyethylenimine enhances delivery of DNA to the cytoplasm. Journal of Controlled Release. 2012;163:1-7.

[36] Bonamin LV. Dados Experimentais que Fundamentam Teorias Interpretativas sobre Ultradiluições. Tributo a Madeleine Bastide. Cultura Homeopática. 2007;(21):29-32.

[37] Wiegant EAC, Wijk $R$ van. Self-recovery and the similia principle: an experimental model. Complementary Therapies in Medicine. 1996;4:90-7.

[38] Wijk R van, Wiegant FAC. Stimulation of self-recovery by similia principle? Mode of testing in fundamental research. British Homoeopathic Journal. 1995;84:131-9.

[39] Almeida LR de. Pesquisa em Bioterápicos. Cultura Homeopática. 2006;(16):6-17.

[40] Berchieri A, Turco WCP, Paiva JB, Oliveira GH, Sterzo EV. Evaluation of isopathic treatment of Salmonella enteritidis in poultry. Homeopathy. 2006;95(2):94-7.

[41] Delbancut A, Dorfman P, Cambar J. Influence of the duration of preteatment with very low concentrations of cadmium on cytotoxicity induced by the metal and on cultured kidney tubular cells. V GIRI Symposium. 1991. p. 1991.

[42] Delbancut A, Barrouillet MP, Maury-Brachet R, Boudou A, Dorfman P, Cambar J. Use of new in vitro tools to study the mechanisms of very low concentration protective effect against cytotoxic cadmium doses. VIII GIRI Symposium. 1994. p. 1994.

(c)) BY-NC-ND Licensed to GIRI

Support: authors declare that this study received no funding

Conflict of interest: authors declare there is no conflict of interest

Received: November 20 th 2013 ; Revised: March 11 ${ }^{\text {st }}, 2014$; Published: September 30 2014.

Correspondence author: Danielle de Macedo Mano, danimmano@yahoo.com.br

How to cite this article: Mano DM, de Oliveira ECV, Leonel AH, Berretta AA. Cationic topical formulations tested in high dilutions offers protective effects in fibroblast cells culture. Int J High Dilution Res [online]. 2014 [cited YYYY Month dd]; 13(48): 147-156. Available from: http://www.feg.unesp.br/ ojs/index.php/ijhdr/article/view/690/724 